\title{
Effect of air drying temperature on phytochemical properties of brown seaweed Bifurcaria bifurcata
}

Arufe, S. V.; Sineiro, J.; Chenlo, F.; Moreira, R.* .

Department of Chemical Engineering, Universidade de Santiago de Compostela, Rúa Lope Gómez de Marzoa, Santiago de Compostela, E-15782, Spain.

*E-mail of the corresponding author: ramon.moreira@usc.es

\begin{abstract}
The purpose of this study was to determine the effects of convective airdrying at different temperatures $\left(35,50,60\right.$ and $\left.75^{\circ} \mathrm{C}\right)$ on the color of Bifurcaria bifurcata (BB) seaweed powders obtained after milling, the antioxidant activity and polyphenolic and carbohydrate content of the aqueous extracts obtained by ultrasound-assisted extraction. BB seaweed powders exhibited significant color differences between powders obtained from $\mathrm{BB}$ dried at $35^{\circ} \mathrm{C}$ (yellowish-green) and 50-75 ${ }^{\circ} \mathrm{C}$ (brown). High air drying temperature (above $60^{\circ} \mathrm{C}$ ) significantly reduced the total polyphenolic, carbohydrate content and scavenging activity of aqueous extracts of BB.
\end{abstract}

Keywords: Phaeophyceae Antioxidant activity Carbohydrates Color Polyphenols 


\section{Introduction}

The safety and toxicity issues related with synthetic antioxidants [1] can explain the increasing interest in natural antioxidants to replace synthetic additives in foods or nutraceuticals. Natural antioxidants are effective in protecting the body against damage caused by Reactive Oxygen Species (ROS) and extending the storage time of food. They have the capability not only to improve oxidative stability but also to provide a wide variety of additional health benefits [2]. They inhibit or prevent the oxidation of a substrate and evolve to protect biological systems against damage induced by ROS.

It has been demonstrated that antioxidant compounds from seaweeds have health benefits such as antimutagenic, anti-viral, amelioration of diabetic complication, bactericides, etc. Some types of polyphenols and tannins (i.e. phlorotannins) have strong antioxidant activities, and they are abundant in brown macroalgae [2]. Regarding the potential uses of brown seaweeds, due to their interesting antioxidant properties, it is necessary to study how the processing (including operations such as collection, preservation (drying) and storage, among others) affects the biological activity of certain compounds. Traditionally, seaweeds are sundried for long periods and the final properties can be altered. The current increase of marine algae production rates requires the application of faster and controlled industrial methods. In this sense, in order to overcome the long periods of natural sun drying (days), several alternatives can be useful such as freeze-drying or convective hot air drying, which is the most widely employed method for preserving biological materials, where the air conditions (temperature, relative humidity and velocity) are controlled [3].

Several authors studied the effect of different drying techniques on the antioxidant properties of extracts of different seaweeds such as Sargassum sp., Kappaphycus alvarezii, Gracilaria chilensis, among others [4,5]. However, no studies assessing the effect of drying conditions on phytochemical properties of Bifurcaria bifurcata were found in the literature. Consequently, the main objective of this work is to determine the effect of the air drying temperature on color and phytochemical properties of brown seaweed Bifurcaria bifurcata.

\section{Materials and Methods}

Bifurcaria bifurcata seaweeds previously dried at $35,50,60$, and $75^{\circ} \mathrm{C}$ in a hot convective air dryer were milled in order to obtain seaweed powders. Milling was carried out using a centrifugal mill (ZM 200, Retsch GMBH, Germany). The rotor speed was adjusted to 8000 rpm and a standard sieve $(500 \mu \mathrm{m})$ was employed. The milled systems obtained at different drying temperatures (BB35P, BB50P, BB60P, and $\mathrm{BB} 75 \mathrm{P}$ ) were stored at $5^{\circ} \mathrm{C}$ in polyethylene plastic bags under vacuum with a vacuum-packer (Sammic V201, Spain) for further utilization. 
Color of obtained powders and their different particle size fractions obtained after sieving (sieves from 40 up to $500 \mu \mathrm{m}$ ) was determined using a colorimeter (Chroma Meter CR-400, Konika Minolta, Japan). Color was measured by means of CIELab coordinates: L* $\left(\right.$ whiteness $\left(\mathrm{L}^{*}=0\right)$ or brightness $\left.\left(\mathrm{L}^{*}=100\right)\right)$, $\mathrm{a}^{*}\left(\right.$ redness $\left(\mathrm{a}^{*}>0\right)$ or greenness $\left(\mathrm{a}^{*}<0\right)$ and $b^{*}$ (yellowness $\left(b^{*}>0\right)$ or blueness $\left(b^{*}<0\right)$ ). Moreover, total color difference parameter $\left(\Delta \mathrm{E}^{*}\right.$, Eq. (1)) for each size fractions (i) was estimated and classified according to [6] using as reference ( $r$ ) the color coordinates of the seaweed powder prior to sieving (whole).

$\Delta \mathrm{E}^{*}=\sqrt{\left(\mathrm{L}_{\mathrm{i}}^{*}-\mathrm{L}_{\mathrm{r}}^{*}\right)^{2}+\left(a_{\mathrm{i}}^{*}-\mathrm{a}_{\mathrm{r}}^{*}\right)^{2}+\left(b_{\mathrm{i}}^{*}-\mathrm{b}_{\mathrm{r}}^{*}\right)^{2}}$

Seaweed aqueous extracts were obtained from the different dried seaweed powders in order to determine the effect of air drying in total polyphenols and carbohydrate content and the antioxidant activity of seaweeds. Samples of powdered seaweed, were processed with an ultrasound sonicator (Hielscher, UIP-1000 hdT, Germany) to enhance the extraction of polyphenols and carbohydrates. All experiments were carried out in batch. The procedure starting with a rehydration step $(15 \mathrm{~min})$ before extraction. Then extraction operation took place using a $200 \mathrm{~mL}$ beaker at controlled temperature $\left(<35^{\circ} \mathrm{C}\right)$ employing a cold water bath to avoid that high temperatures could affect the antioxidant activity. All extractions were performed using water as solvent. The equipment operated with a frequency of 20 $\mathrm{kHz}$ and the irradiation power $(<1000 \mathrm{~W})$ was regulated in the ultrasound generator at $80 \%$ amplitude. The conditions were 4 min of contact time and $30 \mathrm{w} \cdot \mathrm{w}^{-1}$ of liquid-solid ratio. Finally, obtained extracts were centrifuged at $12400 \mathrm{rpm}$ for $15 \mathrm{~min}$ using a high speed laboratory centrifuge (2-15, Sigma, UK), and the supernatant obtained was then filtered by pressure using syringe filters with a pore size of $0.25 \mu \mathrm{m}$ and used for characterization analysis. All seaweed aqueous extracts were analyzed by means of DPPH scavenging activity, total solids, polyphenols and carbohydrate content.

The quantitative determination of total polyphenols content (TP) was measured as phloroglucinol (PHL) equivalents following a colorimetric method [7]. TP was evaluated in reference to raw seaweed powder sample $\left(\mathrm{mg} \mathrm{PHL} \cdot(100 \mathrm{~g} \text { dry powder })^{-1}, \mathrm{TP}_{\mathrm{w}}\right)$ and also to total solids content in the extract $\left(\mathrm{mg} \mathrm{PHL} \cdot(100 \mathrm{~g} \text { dry solids })^{-1}, \mathrm{TP}_{\mathrm{s}}\right)$.

Carbohydrates content of the extracts was determined following a method previously reported [8]. Carbohydrates content was expressed as glucose equivalents (GL) referred to raw seaweed powder sample (mg GL·(100 g dry powder $\left.)^{-1}, \mathrm{CHO}_{\mathrm{w}}\right)$ and also to total solids content in the extract (mg GL·(100 g dry solids $\left.)^{-1}, \mathrm{CHO}_{\mathrm{s}}\right)$.

The DPPH scavenging activity assay measures the capacity of a system to react with a free radical agent (2, 2-diphenyl-1-picrylhydrazyl, DPPH). It was employed the method proposed by Brand-Williams [9]. In its radical form, DPPH. shows an absorption peak at 
$515 \mathrm{~nm}$, but upon reduction by an antioxidant $(\mathrm{AH})$ or a radical species $(\mathrm{R} \cdot)$ the absorption disappears. As the reaction takes time to fully develop, for the determination of the DPPH scavenging activity absorbance is measured every $5 \mathrm{~min}$ until it reaches the stationary state. Scavenging activity, SA, is evaluated by means of Eq. (2):

$S A(\%)=\frac{A_{0}-A_{f}}{A_{0}} \cdot 100$

where $\mathrm{A}_{0}(-)$ is the absorbance at time 0 and $\mathrm{A}_{\mathrm{f}}$ is the absorbance after one hour.

\section{Results and Discussion}

\subsection{Color characterization}

The trends for color parameters values of powders from seaweeds dried at 35, 50, 60 and $75^{\circ} \mathrm{C}$ with the corresponding particle size fractions are displayed in Figure 1.
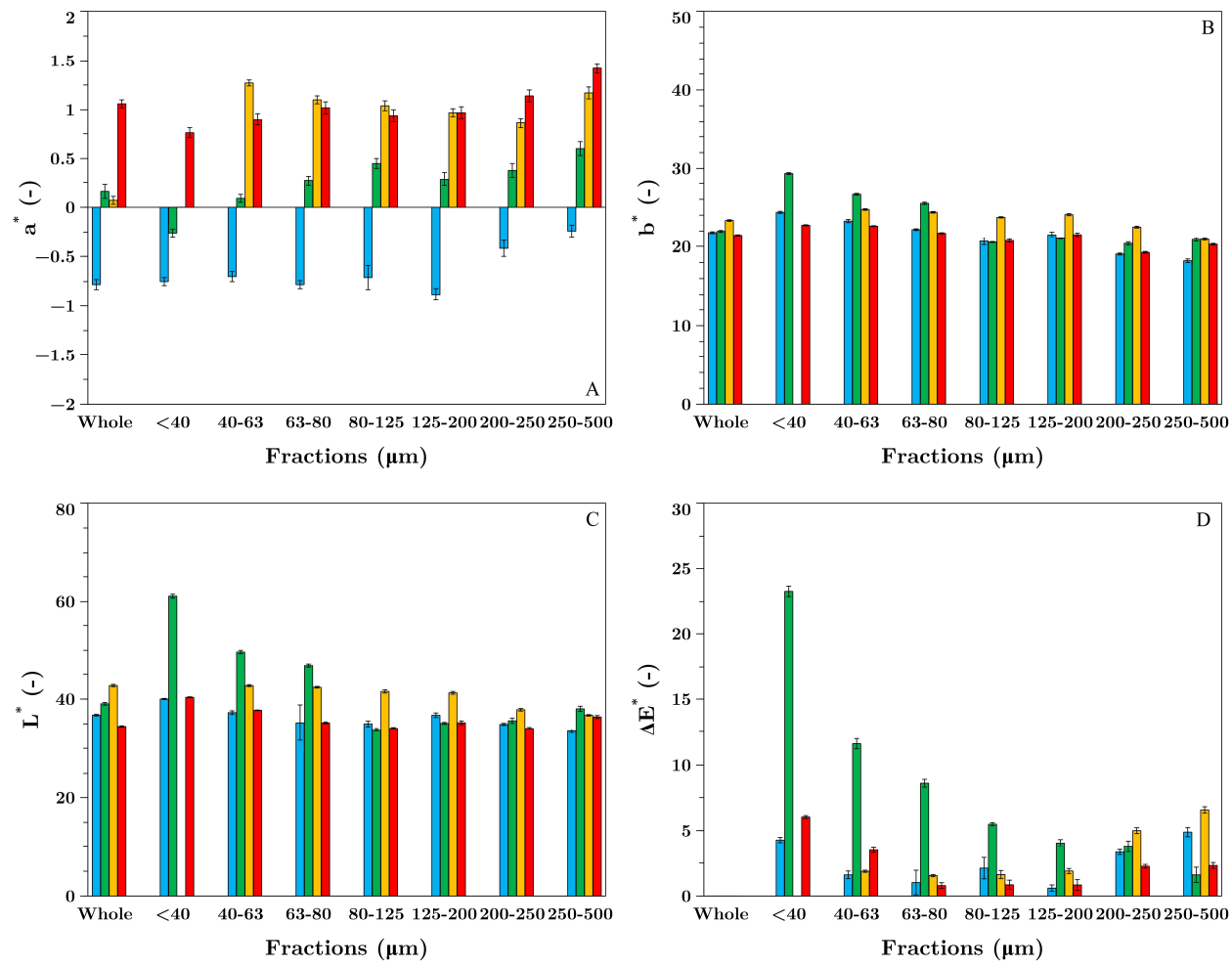

Fig. $1 a^{*}(A), b^{*}(B), L^{*}(C)$ and $\Delta E^{*}(D)$ color parameters of Bifurcaria bifurcata seaweed powders obtained after drying at different temperatures $35^{\circ} \mathrm{C}(\square), 50^{\circ} \mathrm{C}(\square), 60^{\circ} \mathrm{C}(\square)$ and $75^{\circ} \mathrm{C}(\square)$. 
Specifically, a* parameter values increased with increasing drying temperature. It is noticiable that the trend of $\mathrm{a}^{*}$ changes from green to red with drying temperatures above $35^{\circ} \mathrm{C}$. Regarding particle size effect, $\mathrm{a}^{*}$ increased in general for all assessed seaweed powders.

The effect of drying temperature did not cause relevant changes in $b^{*}$ values. All seaweed powders have a yellowness predominance $\left(b^{*}>0\right)$. Regarding color properties of size fractions, $b^{*}$ slightly decreased for all systems as mean size increased. Both trends might be related to the presence of still structurally undamaged parts of the seaweed in the biggest particles.

It can be seen that $\mathrm{L}^{*}$ parameter significantly decreased with increasing particle size up to 200-250 $\mu \mathrm{m}$ for all drying temperatures. Nevertheless, regarding drying temperature effect, no clear trends were observed.

The evaluation of total color difference $\left(\Delta \mathrm{E}^{*}\right)$ trend showed minimum values at intermediate particle sizes (from 80 to $200 \mu \mathrm{m}$ ). Particularly, the found color difference can be classified as small $\Delta \mathrm{E}^{*}=0.60,1.60,1.54$, and 0.79 for BB35P, BB50P, BB60P, and BB75P, respectively, according to [6].

Summarizing, drying temperature effect on color properties of Bifurcaria bifurcata seaweed powders modifies from greenness to redness predominance at drying temperatures above $35^{\circ} \mathrm{C}$.

\subsection{Seaweeds extracts}

\subsubsection{Total polyphenols content}

Total polyphenols content values (TP) of aqueous extracts from Bifurcaria bifurcata dried at different temperatures are shown in Figure 2.
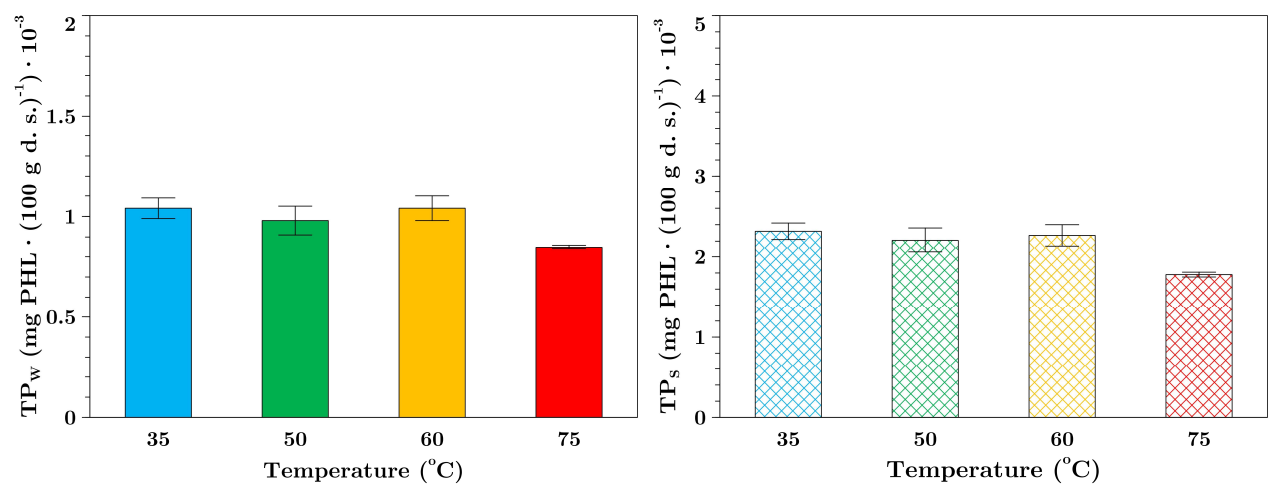

Fig. 2 Total Polyphenols (TP) of aqueous extracts of Bifurcaria bifurcata powders formerly dried at different temperatures $\left(35^{\circ} \mathrm{C}(\square), 50^{\circ} \mathrm{C}(\square), 60^{\circ} \mathrm{C}(\square)\right.$ and $\left.75^{\circ} \mathrm{C}(\square)\right)$ : referred to raw powder $(\mathrm{mg}$ 


\section{$P H L \cdot(100 \mathrm{~g} \text { dry powder })^{-1}, \mathrm{TP}_{w}(\mathrm{left})$ and total solids content in the extract (mg PHL $\cdot(100 \mathrm{~g}$ dry solids) $)^{-1}, \operatorname{TP}_{s}$ (right).}

It can be observed that $\mathrm{TP}_{\mathrm{w}}$ content of Bifurcaria bifurcata extracts did not significantly change when drying with air-drying temperatures lower than $60^{\circ} \mathrm{C} . \mathrm{TP}_{\mathrm{s}}$ in the extracts showed the same trend. The fact that both parameters, one referred to raw powder $\left(\mathrm{TP}_{\mathrm{w}}\right)$ and the other to total solids content in the extract $\left(\mathrm{TP}_{\mathrm{s}}\right)$ indicates that the significant differences in TP can be attributed to the different temperatures employed during drying and not to differences in the extraction yields.

Extracts obtained from seaweeds dried at $75^{\circ} \mathrm{C}$ rendered the lowest $\mathrm{TP}$ values indicating that air-drying temperature clearly influences TP content of the extracts. The use of a hot air-drying technique can lead to thermally-promoted physical and chemical processes i.e. structural collapse of cells during drying, textural modifications, migrations of chemical compounds, accumulation of substances in cell membranes and several chemical reactions) during this step, which make difficult the subsequent extraction of phenolic compounds.

\subsubsection{Carbohydrate content}

The effect of drying temperature on carbohydrate content $(\mathrm{CHO})$ of extracts can be observed in Figure 3.
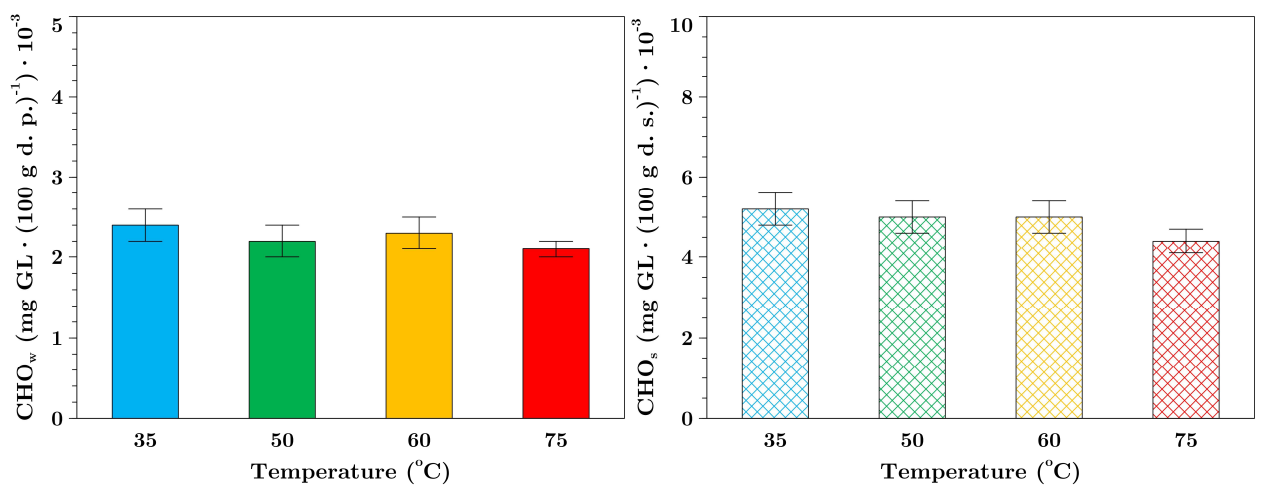

Fig. 3 Carbohydrate content (CHO) of aqueous extracts of Bifurcaria bifurcata powders formerly dried at different temperatures $\left(35^{\circ} \mathrm{C}(\square), 50^{\circ} \mathrm{C}(\square), 60^{\circ} \mathrm{C}(\square)\right.$ and $\left.75^{\circ} \mathrm{C}(\square)\right)$ : referred to raw powder (mg GL:(100 g dry powder) $)^{-1}, \mathrm{CHO}_{w}$ (left) and total solids content in the extract (mg GL $\cdot(100 \mathrm{~g}$ dry solids) $)^{-1}, \mathrm{CHO}_{\text {s }}$ (right).

As in the case of TP content, air-drying temperatures higher than $60^{\circ} \mathrm{C}$ significantly decreased $\mathrm{CHO}$ content. The extracts obtained from BB75 showed the minimum values of $\mathrm{CHO}_{\mathrm{w}}$ and $\mathrm{CHO}_{\mathrm{s}}(2103 \pm 143 \mathrm{mg}$ eq. GL/100 g dry powder and $4426 \pm 301 \mathrm{mg}$ eq. GL/100 $\mathrm{g}$ dry solid, respectively) and the maximum value of $\mathrm{CHO}$ content was observed for BB35 (2394 $\pm 167 \mathrm{mg}$ eq. GL/100 g dry powder and $521 \pm 363 \mathrm{mg}$ eq. GL/100 g dry solid, respectively). These results might be related to the physical and chemical processes that 
may difficult the extraction of carbohydrates, in the same mode than the phenolic compounds. Similarly, to the TP content results, $\mathrm{CHO}$ obtained results indicated that their differences should be attributed to the effect of drying conditions (temperature) and not to the differences in the extraction yields, because trends of $\mathrm{CHO}_{\mathrm{w}}$ and $\mathrm{CHO}_{\mathrm{s}}$ values with temperature were similar.

\subsubsection{Antioxidant activity}

The antioxidant activity of aqueous seaweed extracts was evaluated by means of total DPPH radical scavenging activity (SA), Table 1.

Table 1. Radical scavenging activity (SA) of extracts from Bifurcaria bifurcata seaweeds dried at different temperatures.

\begin{tabular}{cc}
\hline Drying Temperature $\left({ }^{\mathbf{0}} \mathbf{C}\right)$ & $\mathbf{S A}(\boldsymbol{\%})$ \\
\hline 35 & $58.3 \pm 2.3^{\mathrm{a}}$ \\
50 & $54.7 \pm 7.2^{\mathrm{a}}$ \\
60 & $55.4 \pm 0.7^{\mathrm{a}}$ \\
75 & $45.3 \pm 2.5^{\mathrm{b}}$
\end{tabular}

*Data are presented as means \pm standar deviation. Data value of each parameter with different superscript letters in columns are significantly different $(\mathrm{P} \leq 0.05)$.

The effect of air drying temperature was very similar to the previously described for TP and CHO. Air drying temperatures higher than $60^{\circ} \mathrm{C}$ significantly decreased the SA of Bifurcaria bifurcata aqueous extracts. The reduction in TP content and SA at high drying temperatures may be due to several factors: release of phenolic compounds bound to cell wall during drying; thermal degradation by oxidative enzymes; phenolic compounds may rapidly degrade at drying temperatures above $40^{\circ} \mathrm{C}$; binding of polyphenols to other substances (proteins) or alterations in their chemical structure $[5,10,11]$.

The observed trend of SA and TP was previously reported in literature by other authors. Tello-Ireland et al. [5] reported a loss of antioxidant activity when drying Gracilaria chilensis at high temperatures $\left(70^{\circ} \mathrm{C}\right)$ and Gupta et al. [10] a $30 \%$ decrease in TP of Himanthalia elongata when dried at $40^{\circ} \mathrm{C}$ in comparison with fresh seaweed.

\section{Conclusions}

Air drying temperature has a clear effect on phytochemical properties of brown seaweed Bifurcaria bifurcata. Regarding color properties, temperatures of drying higher than $35^{\circ} \mathrm{C}$ enhance a change from greenness to redness predominance on the color of the seaweeds powders. In the case of total polyphenolic and carbohydrate contents and scavenging activity of the aqueous extracts, all parameters are significantly reduced when drying at temperatures higher than $60^{\circ} \mathrm{C}$. These results clearly define the drying conditions to be employed for this brown seaweed when specific properties of the final powders or extracts are required. 


\section{Acknowledgements}

The authors acknowledge the financial support of the Ministry of Economy and Competitiveness of Spain and European Regional Development Fund (ERDF) of European Union by the research project (CTQ 2013-43616/P).

\section{References}

[1] Khairy, H.M.; El-Sheikh, M.A. Antioxidant activity and mineral composition of three mediterranean common seaweeds from Abu-qir bay, Egypt. Saudi Journal of Biological Sciences, 2015, 22, 623-630.

[2] Cornish, M.L.; Garbary, D.J. Antioxidants from macroalgae: potential applications in human health and nutrition. ALGAE, 2004, 25, 155-171.

[3] Santchurn S.J.; Arnaud E.; Zakhia-Rozis N.; Collignan, A. Drying: principles and applications. In: Huy YH (ed) Handb. Meat meat process, 2nd edn. CRC Press, Boca Raton 2012; 506.

[4] Ling, A.L.M.; Yasir, S.; Matanjun, P.; Abu Bakar, M.F. Effect of different drying techniques on the phytochemical content and antioxidant activity of Kappaphycus alvarezii. Journal of Applied Phycology, 2015, 27, 1717-1723.

[5] Tello-Ireland, C.; Lemus-Mondaca, R.; Vega-Gálvez, A.; López, J.; Di Scala, J. Influence of hot-air temperature on drying kinetics, functional properties, color, phycobiliproteins, antioxidant capacity, texture and agar yield of alga Gracilaria chilensis. LWT - Food Science and Technology, 2011, 44, 2112-2118.

[6] Adekunte, A.O.; Tiwari, B.K.; Cullen, P.J.; Scannell, A.G.M.; O'Donnell, C.P. Effect of sonication on color, ascorbic acid and yeast inactivation in tomato juice. Food Chemistry, 2010, 122, 500-507.

[7] Singleton, V.L.; Rossi, J.A. Colorimetry of total phenolics with phosphomolybdicphosphotungstic acid reagents. American Journal of Enology and Viticulture, 1965, $16,144-158$.

[8] DuBois, M.; Gilles, K.A.; Hamilton, J.K., Rebers, P.A.; Smith, F. Colorimetric method for determination of sugars and related substances. Analytical Chemistry, 1956, 28, $350-356$.

[9] Brand-Williams, W.; Cuvelier, M.; Berset, C. Use of a free radical method to evaluate antioxidant activity. LWT - Food Science and Technology, 1995, 28, 25-30.

[10] Gupta, S.; Cox, S.; Abu-Ghannam, N. Effect of different drying temperatures on the moisture and phytochemical constituents of edible irish brown seaweed. LWT - Food Science and Technology, 2011, 44, 1266-1272.

[11] Le Lann, K.; Jégou, C.; Stiger-Pouvreau, V. Effect of different conditioning treatments on total phenolic content and antioxidant activities in two Sargassacean species: Comparison of the frondose Sargassum muticum (yendo) fensholt and the cylindrical Bifurcaria bifurcata r. ross. Phycological Research, 2008, 56, 238-245. 